\title{
Selection of Casting Materials for Working Parts of Machines for The Forestry Sector
}

\author{
Zenon Pirowski ${ }^{1}$, Adam Bitka ${ }^{1}$, Malgorzata Grudzien Rakoczy ${ }^{1}$, Marcin Malysza ${ }^{1}$, Stanislaw \\ Pysz $^{1}$, Piotr Wieliczko ${ }^{1}$ and Dorota Wilk Kolodziejczyk ${ }^{1,2 *}$ \\ ${ }^{1}$ Lukasiewicz Research Network Krakow Institute of Technology, Poland \\ ${ }^{2}$ AGH University of Science and Technology, Poland
}

*Corresponding author: Dorota Wilk Kolodziejczyk, Lukasiewicz Research Network Krakow Institute of Technology, AGH University of Science and Technology, Poland.

To Cite This Article: Stanislaw Pysz, Piotr Wieliczko, Dorota Wilk Kolodziejczyk, Selection of Casting Materials for Working Parts of Machines for The Forestry Sector. Am J Biomed Sci \& Res. 2021 - 11(6). AJBSR.MS.ID.001691. DOI: 10.34297/AJBSR.2021.11.001691.

Received: 眥 October 20, 2020; Published: 眥 February 08, 2021

\begin{abstract}
The article was created as a result of the work of the TECHMATSTRATEG 1 "Modern Material Technologies" Program as part of the project with the acronym INNOBIOLAS entitled "Development of innovative working elements of machines in the forestry sector and biomass processing based on high-energy surface modification technologies of the surface layer of cast elements"; agreement No. TECHMATSTRATEG1/348072/2/ NCBR/2017.

The article discusses the procedure for selecting casting materials that can meet the high operational requirements of working tools of mulching machines: transfer of high static and dynamic loads, resistance to tribological wear, corrosion resistance in various environments. The mulching process was briefly described, then the alloys were selected for experimental tests, model alloys were made and per-form material tests were carried out in terms of functional and technological properties. The obtained results allowed to select the alloy whereof the test castings were made.
\end{abstract}

\section{Introduction}

According to accepted international standards, the forest area in Poland is over 9.35 million hectares. In recent years, both in Poland and in the European Union countries, the need for new afforestation and wasteland reclamation processes has been increasing. This is due to the need to care for the natural environment, to reduce the greenhouse effect, as well as to further improve life, especially in urbanized areas [1]. Proper management of forest resources requires the use of specialized equipment and devices with a service life significantly exceeding the standards for other machines. In particular, it is necessary to significantly increase the quality and durability of the working elements of these devices. Tools of the forestry sector should be characterized by high strength and plastic parameters, especially high impact toughness, as well as excellent tribological properties and corrosion resistance.

The aim of the project is to use casting technology in combination with the technology of surfacing the working layer in the production of tools for the forestry sector. One of the most important forest work is mulching. Mulching is a conservation procedure aimed at protecting the soil against degradation and maintaining its productivity by creating the so-called mulch, i.e. a protective soil cover placed on its surface in order to reduce the adverse impact of climatic factors [2]. This article discusses the selected casting alloys for the tools for flail mowers (mulchers and shredders) implemented in the new design. These tools include, among others, hammer heads for meadow, forest and roadside mulchers, as well as hammer heads for forest mulchers. Examples of mulching machines are shown in Figures 1-3.

\section{Why casting alloys?}

The casting technology makes it much easier to model and construct elements, even of very com-plex shapes. Such material and technological conversion allow for: 
1. decreasing of technology costs (replacement of welded and forged elements with cheaper castings),

2. increasing durability and quality,

1. increase of modernity and competitiveness of domestic products on the European market,

2. reduce the operating costs of machines and devices by improving the quality of the final product, making it more competitive.

Examples of this constructional and material-technological conversion has been described in a number of publications [e.g. 3, $4,5,6,7]$ being the result of cooperation between PIMR constructors (currently SBLPIMR) and FRI technologists (currently SBLKIT) as part of the implementation of joint research and development projects.

The works described in this article relied on selecting, producing and testing modern casting materials in terms of optimizing their technological and functional properties. Obtaining a casting alloy in terms of its application for the new tools implemented in the project required at the initial stage of implementation to conduct research on alloys previously used for this type of tools.

\section{Selection of Alloys for Tests}

The selection of casting material for elements of various machines and devices has been the subject of research work carried out for many years in Lukasiewicz - Krakow Institute of Technology (formerly the Foundry Research Institute). Examples of such activities related to the constructional and material-technological conversion have been described, inter alia, for alloys for elements operating under conditions of high-temperature wear in publications [12-16], and for alloys exposed to tribological wear, which are the subject of the research of the INNOBIOLAS project, in [1 3-7\&17]. Realizing this project, the mechanical properties of 15 different grades of steels resistant to tribological wear from the most common groups of alloys for this purpose were analyzed: Roex, Hardox and SAAB Boner. On the basis of the normative mechanical prop- erties of these materials (yield point, elongation, hardness and impact tough-ness), it was found that the most favorable parameters for working of abrasive wear in impact conditions has Hardox 450 steel [1], which was assumed as a reference for the selection of appropriate alloy cast grades.

According the intentions and aim of the project, the developed tools are cast tools. By analyzing the relevant Polish and European standards for abrasion-resistant cast steel grades, 11 such alloys were selected for the evaluation of their properties. Carrying out the evaluation of these materials similar to that described in [1] in the case of standardized steel grades, two grades of cast steel performing the assumed criterion of mechanical properties $\left(\mathrm{R}_{\mathrm{p} 0}{ }_{2}\right.$ $\geq 800 \mathrm{MPa}, \mathrm{A} \geq 7 \%$ ) were selected. For this alloys designated for experimental tests a point value higher than the Hardox 450 point value (32,22 assigned points). These are cast steel from the French standard [8]: 30MCDB64-M-I and 30NSCDV86 M-I with a point value of $\mathbf{3 3 , 5 0}$ and $\mathbf{3 4 , 2 5}$ respectively. The standard chemical composition of these alloys is shown in Table 1.

In the design assumptions, the implemented cast tools must, in terms of strength and usability, at least match the forged and welded tools used so far. For comparative material and operational tests were purchased from the national leaders' distributors currently on the market: Mader Serwis - Wroclaw, AGROMAREK - Skrzyszow, GRANIT PARTS - Poznan and PHU P. CZYZ - Lubowo, over 30 items of various types of tools (hammerheads) for the forestry sector. Their chemical composition was analyzed using the Thermo Scientific NITON XL3t 900S GOLDD device, and the average results obtained from this analysis are presented in Table 2.

\section{Material Research}

In the following part of the work, model melts of selected test alloys were made in laboratory conditions. These melts were performed in an open RADYNE induction furnace with a crucible capacity of $40 \mathrm{~kg}$ of metal charge and an inert crucible lining. The received chemical composition of the performed heats is compared in Table 3.

Table 1: Standard chemical composition of cast steel grades selected for testing [8].

\begin{tabular}{|c|c|c|c|c|c|c|c|c|c|c|}
\hline \multirow{2}{*}{ Alloy } & \multicolumn{10}{|c|}{ The content of alloying additions; wt \% } \\
\hline & C & $\mathbf{S i}$ & Mn & $\mathbf{P}$ & $\mathbf{S}$ & $\mathbf{C r}$ & $\mathbf{N i}$ & Mo & $\mathbf{V}$ & B \\
\hline \multirow{2}{*}{ 30MCDB64-M-I } & 0,23 & $\max$. & 1,30 & $\max$. & $\max$. & 0,40 & \multirow{2}{*}{-} & 0,40 & \multirow{2}{*}{ - } & 0,003 \\
\hline & 0,33 & 0,60 & 1,80 & 0,040 & 0,035 & 1,00 & & 0,60 & & 0,006 \\
\hline \multirow{2}{*}{ 30NSCDV86-M-I } & 0,26 & 1,45 & 0,60 & max. & $\max$. & 0,65 & 1,65 & 0,30 & 0,05 & \multirow{2}{*}{-} \\
\hline & 0,33 & 1,80 & 1,00 & 0,040 & 0,035 & 0,90 & 2,00 & 0,45 & 0,15 & \\
\hline
\end{tabular}

Table 2: Average chemical composition of the reference tools.

\begin{tabular}{|c|c|c|c|c|c|}
\hline \multirow{2}{*}{ Parameter } & \multicolumn{5}{|c|}{ The content of alloying additions; wt\% } \\
\cline { 2 - 6 } & C & Si & Mn & Cr & B \\
\hline average & 0,35 & 0,41 & 1,23 & 0,34 & 0,004 \\
\hline minimum & 0,28 & 0,21 & 0,70 & 0,07 & 0,000 \\
\hline
\end{tabular}




\begin{tabular}{|c|c|c|c|c|c|}
\hline maximum & 0,57 & 0,82 & 1,36 & 0,54 & 0,006 \\
\hline stand. dev. & 0,080 & 0,162 & 0,168 & 0,094 & 0,0017 \\
\hline
\end{tabular}

\begin{tabular}{|c|c|c|c|c|c|c|c|c|c|}
\hline \multirow{2}{*}{ Parameter } & \multicolumn{9}{|c|}{ Contents of admixtures; wt\% } \\
\cline { 2 - 11 } & $\mathbf{C u}$ & $\mathbf{N i}$ & $\mathbf{V}$ & $\mathbf{M o}$ & $\mathbf{T i}$ & $\mathbf{N b}$ & $\mathbf{Z r}$ & $\mathbf{Z n}$ & $\mathbf{S n}$ \\
\hline average & 0,115 & 0,044 & 0,005 & 0,018 & 0,031 & 0,000 & 0,001 & 0,005 & 0,002 \\
\hline minimum & 0,000 & 0,000 & 0,000 & 0,002 & 0,000 & 0,000 & 0,000 & 0,000 & 0,000 \\
\hline maximum & 0,249 & 0,117 & 0,009 & 0,151 & 0,058 & 0,006 & 0,003 & 0,029 & 0,019 \\
\hline stand. dev. & 0,079 & 0,049 & 0,003 & 0,025 & 0,020 & 0,001 & 0,001 & 0,007 & 0,006 \\
\hline
\end{tabular}

Table 3: The obtained chemical composition of the made model alloys.

\begin{tabular}{|c|c|c|c|c|c|c|c|c|c|c|}
\hline \multirow{2}{*}{ Alloy } & \multicolumn{9}{|c|}{ The content of alloying additions; wt\% } \\
\cline { 2 - 26 } & $\mathbf{C}$ & $\mathbf{S i}$ & $\mathbf{M n}$ & $\mathbf{P}$ & $\mathbf{S}$ & $\mathbf{C r}$ & $\mathbf{N i}$ & Mo & V & B \\
\hline 30MCDB64-M-I & 0,25 & 0,37 & 1,41 & 0,023 & 0,023 & 1,54 & 0,05 & 0,440 & - & 0,007 \\
\hline 30NSCDV86-M-I & 0,47 & 1,76 & 0,72 & 0,017 & 0,012 & 0,94 & 1,740 & 0,570 & 0,140 & - \\
\hline
\end{tabular}

Table 4: Mechanical properties and density of the manufactured model alloys.

\begin{tabular}{|c|c|c|c|c|c|c|c|c|c|c|}
\hline \multirow{4}{*}{ Alloy } & \multicolumn{9}{|c|}{ Designated parameter } & \multirow{4}{*}{ The heat treatment } \\
\hline & $\mathbf{R}_{\mathrm{m}}$ & $\mathbf{R}_{\mathrm{p} 0,2}$ & A & $\mathbf{z}$ & HB & KV & $\mathbf{E}$ & $\mathbf{n}$ & $\mathbf{r}$ & \\
\hline & [MPa] & [MPa] & [\%] & [\%] & {$[-]$} & $\left(-40^{\circ} \mathrm{C}\right)$ & [GPa] & {$[-]$} & {$\left[\mathrm{g} / \mathrm{cm}^{3}\right]$} & \\
\hline & & & & & & [J] & & & & \\
\hline \multirow{4}{*}{ 30MCDB64-M } & \multirow{2}{*}{1514} & \multirow{2}{*}{1415} & \multirow{2}{*}{8,4} & \multirow{2}{*}{25,1} & \multirow{2}{*}{409} & \multirow{2}{*}{15,3} & \multirow{2}{*}{188} & \multirow{2}{*}{0,27} & \multirow{2}{*}{7,81} & water quenching \\
\hline & & & & & & & & & & low tempering \\
\hline & \multirow{2}{*}{965} & \multirow{2}{*}{861} & \multirow{2}{*}{13,4} & \multirow{2}{*}{47,1} & \multirow{2}{*}{299} & \multirow{2}{*}{20,5} & \multirow{2}{*}{-} & \multirow{2}{*}{-} & \multirow{2}{*}{7,80} & water quenching \\
\hline & & & & & & & & & & high tempering \\
\hline \multirow{8}{*}{ 30NSCDV86-M } & \multicolumn{4}{|c|}{ brittle alloy } & \multirow{2}{*}{586} & \multirow{2}{*}{2,9} & & & \multirow{2}{*}{$\begin{array}{c}\text { 7,66 } \\
\text { tempering }\end{array}$} & water quenching \\
\hline & \multicolumn{4}{|c|}{ (samples break during testing) } & & & & & & \\
\hline & \multirow{3}{*}{1674} & \multirow{3}{*}{1486} & \multirow{3}{*}{0,8} & \multirow{3}{*}{0,5} & \multirow{3}{*}{362} & \multirow{3}{*}{6,2} & \multirow{3}{*}{202} & \multirow{3}{*}{0,29} & & preliminary annealing \\
\hline & & & & & & & & & 7,68 & water quenching \\
\hline & & & & & & & & & & double tempering \\
\hline & & & & & & & & & & preliminary annealing \\
\hline & 1683 & 1537 & 2,5 & 4,4 & 349 & 7,8 & 197 & 0,27 & 7,67 & quenching in oil \\
\hline & & & & & & & & & & double tempering \\
\hline
\end{tabular}

Table 5: Test results of the mechanical properties of the forged commercial (reference) hammers material.

\begin{tabular}{|c|c|c|c|c|c|c|c|}
\hline \multirow{3}{*}{ Material } & \multicolumn{7}{|c|}{ Designated parameter } \\
\hline & \multirow{2}{*}{$\begin{array}{c}\mathrm{R}_{\mathrm{m}} \\
{[\mathrm{MPa}]}\end{array}$} & \multirow{2}{*}{$\begin{array}{c}\mathrm{R}_{\mathrm{p} 0,2} \\
{[\mathrm{MPa}]}\end{array}$} & A & $\mathrm{Z}$ & HRC & HB & $\mathrm{KV}\left(-40^{\circ} \mathrm{C}\right)$ \\
\hline & & & [\%] & [\%] & {$[-]$} & {$[-]$} & [J] \\
\hline steel type Hardox 450 & 1282 & 1120 & 8,6 & 43,6 & 35,0 & 325 & 15,8 \\
\hline
\end{tabular}

A separate research problem was to develop a method of carrying out the necessary thermal treatments of the model alloys (selection of temperature and time parameters of these processes) ensuring obtaining the structurally required properties of the material itself. The material is intended for the further part of the design work consisting in combining this native material of casting tools with the hardened layer of working surfaces [10].
The tested alloys were subjected to multi-variant thermal treatments. Annealing treatments were carried out in an electric resistance furnace POK73.1. The austenitization treatments were carried out in an electric Multiterm N41 / M resistance furnace under an argon atmosphere. The tempering treatments were carried out in the Multiterm N41 / M electric resistance furnace (for a temperature of $600^{\circ} \mathrm{C}$ in an argon atmosphere, and for a lower temperature 
in an air atmosphere). The following thermal treatments were used for individual alloys:

a) cast steel 30MCDB64-M (designation of the cast condition not taking into account normative thermal treatments):

1. variant 1 : water quenching; low tempering,

2. variant 2: water quenching; high tempering,

b) cast steel 30NSCDV86-M (designation of the cast condition not taking into account normative thermal treatments):

variant 1 : water quenching; tempering,

variant 2: preliminary annealing; water quenching; double tempering,

variant 3: preliminary annealing; quenching in oil; double tempering,

The heat treated model alloys were subjected to a static tensile test, impact strength and hardness measurements as well as densi- ty measurements. The results of these tests are presented in Table 4. Mechanical properties were also tested on the reference material taken from the purchased mulcher flail hammers, and the results are presented in Table 5.

The manufactured alloys were subjected to laboratory corrosion and tribological tests [17] and thermal characteristics of thermophysical properties [9] necessary for numerical analysis of pouring and solidification processes in the virtual development of the casting technology of the implemented tools were prepared.

Based on the results of the laboratory tests, the 30MCDB64-M-I cast steel was selected for techno-logical tests.

\section{Numerical analysis}

Within the project, the construction of many types of the mulching hammerhead, forestry mulchers was developed. Six of them were selected for realization and implementation, as shown in Figure 4.

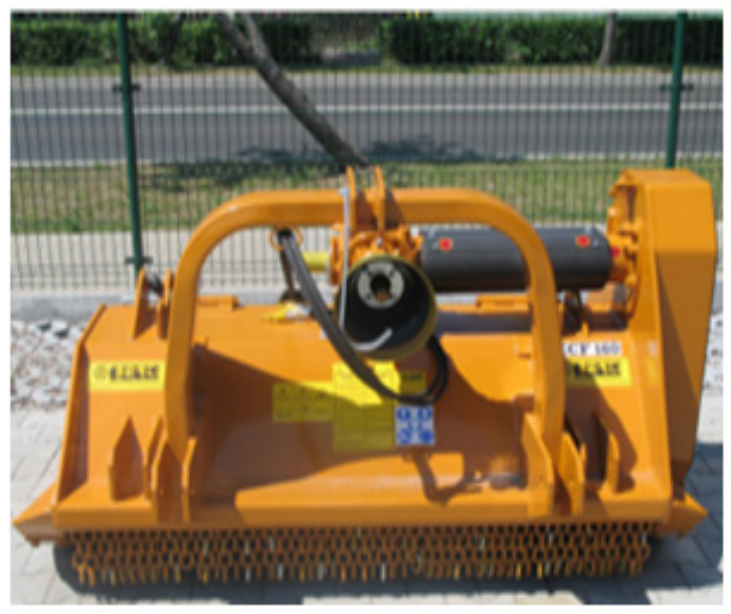

Figure 1: Mulcher for mulching meadows.

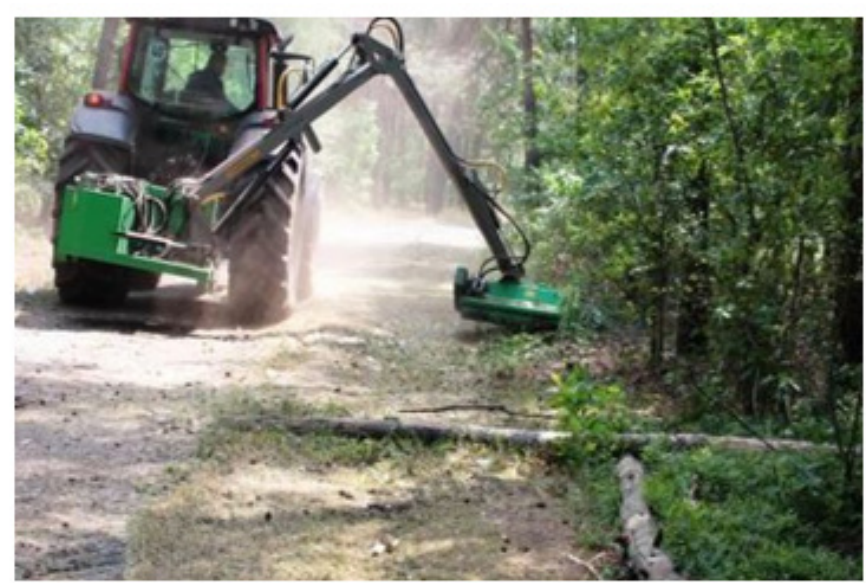

Figure 2: Mulcher for mulching of roadside. 


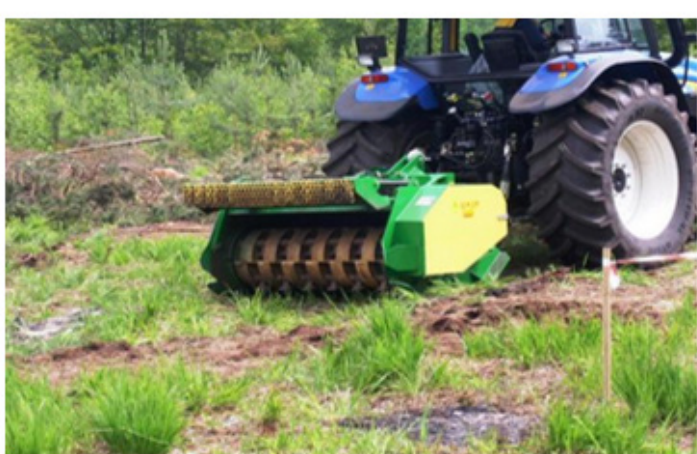

Figure 3: Mulcher for mulching forest areas
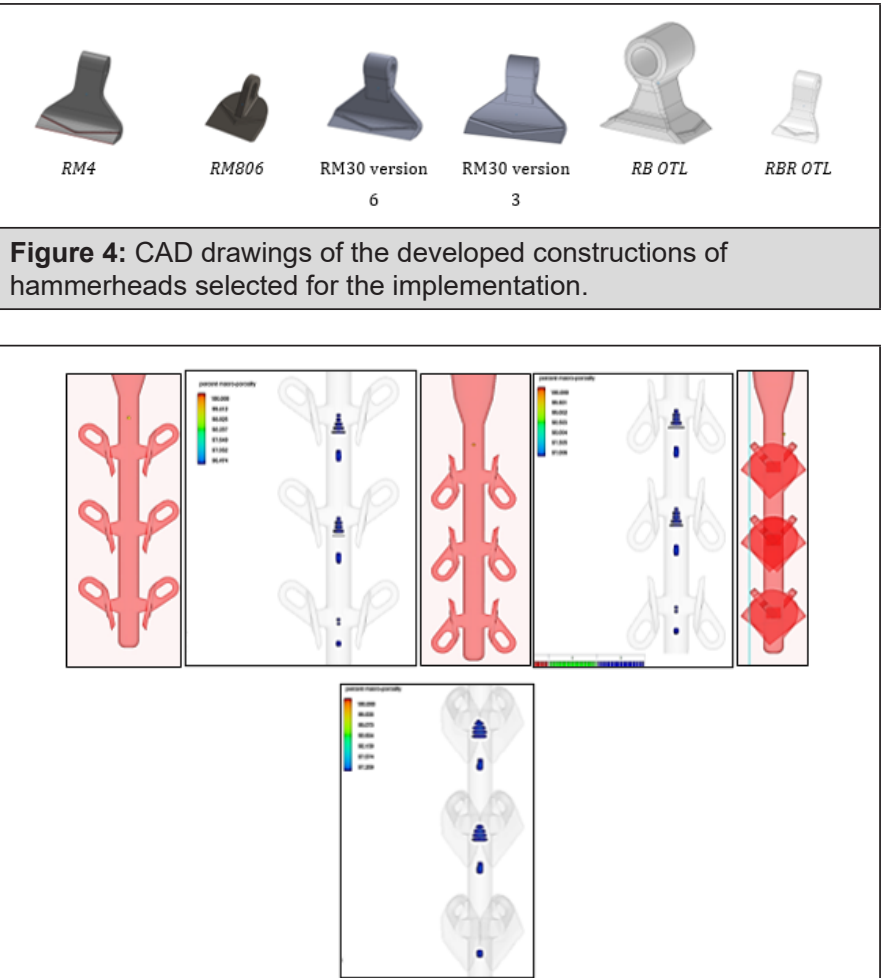

Figure 5: Analysis of various variants of the mulcher RM806 mode positions.

Using numerical analysis methods was developed the foundry technology of for these tools production. This article only discusses examples. Based on the geometry of the constructed tool, the concepts of casting technology were proposed, which were then used in computer simulation to determine the area of possible shrinkage porosities.

Examples of various concepts for the location of the wax model of the RM806 hammer in relation to the gating system and the evaluation of the effect of changes in this orientation on the contraction porosity in the model-gating system are shown in Figure 5.

The numerical analysis of the solidification process showed that in this case the orientation of the model did not affect the possibili- ty of shrinkage defects. This is due to the gating system's much larger hot spot than the casting. The construction of the RM806 hammer is discussed in detail in the patent application under the name "Mulcher hammer and its manufacture" dated October 25, 2019 the patent application was marked with the number: P.431587 [11].

In the case of the RM4 mulcher, two technological concepts were analyzed, for three and four models in the gating system, shown later in the article in Figure 9. Both cases give the positive results of compact structure castings. For economic reasons a four-element concept was chosen. Due to the very similar shapes of the other tools, the casting technology for them was designed in a very similar way.

The only detail that differs in shape from the others is the tool marked RB OTL, characterized by a wide base. Two possible concepts of its casting technology were analyzed: one or four castings in a set. The concept of one casting is dictated by the fact that the casting cross-section requires an appropriate feeding of the casting. The second concept is more economical, but technologically more difficult in terms of making foundry moulds. Using the numerical analysis method, an attempt was made to virtually evaluate the microstructure of the casting and to estimate the basic mechanical properties of the cast alloy.

Cast steel 30MCDB64-M-I intended for casting of implemented tools is characterized by a Rp0.2 / Rm ratio. The virtual solidification curves of this alloy, (example shown in Figure 6), in the thicker and thinner wall of the RM4 hammer casting show that the solidification rate at these points is significantly different, which influences on the differences in the final strength properties. The tensile strength (Rm) can change from 600 to $800 \mathrm{MPa}$ depending on the wall thickness.

At the end of (thin walled) zone is occurring in the tendency to form an increased amount of perlite as shown in Figure 7. The hammer blade has a very thin wall at the end of the tool. This can cause the formation of carbides, which will greatly increase strength, but will significantly reduce plasticity. The heat treatment compensates for such large differences in properties in the cross-section of the casting.

The performed numerical analysis on the example of the RM4 mulcher casting also allowed for a virtual evaluation of the size and distribution of residual stresses can result from in the solidification and cooling process of casting. For this purpose, creates CAD solids in the SolidWorks program were used, which were also used to prepare the concept of the casting technology and to evaluate the porosity. The MAGMA Soft software was used for evaluating the size and distribution of stresses. Technological assumptions prepared for precision casting process were analyzed. The computational iteration includes the properties of the ceramic mass, which 
is a layered casting mould containing the gating system and castings. The aim of this analysis was to virtually evaluation the size and distribution of residual stresses of the selected cast steel grade (30MCDB64-M-I) for solidifying casting on the example of an RM4 mulcher.

Figure 8 illustrates, respectively: the selected tool, the technological concept and the virtual layered ceramic mould for one of the analyzed technological variants.

Based on the of the geometry of the constructed tool, the previously mentioned two concepts of casting technology were proposed, which were used for evaluating the size and distribution of residual stresses that result from the casting process. The advantage of using computer programs to simulate technological processes is the possibility of predicting stresses occurring during solidification, which may cause deformation or cracking of castings. On the example of the RM4 mulcher, the influence of the change in the orientation of the casting in the gating system set was analyzed, what has been presented in Figures $9 \& 10$.

Visualization of stress simulation results shows the areas ex- posed to excessive stress concentration. Simulations A1 and B1 show the picture of reduced stress (Von Mises) for two technological concepts. In the case of the A concept, these stresses do not exceed $37 \mathrm{MPa}$, which for the analyzed alloy is significantly below its yield point. For the B concept, this value reaches a much higher value, i.e. $100 \mathrm{MPa}$, but it still does not affect the formation of cracks, because the material has a much higher yield point.

Another feature presented in Figure 9 is the distribution of tensile stresses in the initial stage after the metal solidification (Initial Tensile Strength) - simulations A2 and B2. Its presents in which areas deformations can occur in the process of cooling the casting. For the technological concept $\mathrm{A}$, the danger of deformation rises at the ends of the tool and reaches a maximum value of about $57 \mathrm{MPa}$. The material characteristics show that this value is also lower than the properties of this alloy. It's similar to the concept B. In such an arrangement, this value reaches about $64 \mathrm{MPa}$ and is also located on the protruding parts of the tool. Such a stress location for this tool is due to its geometry, as there is a significant diversification of the cross-sections in the adjacent areas of the casting (the smallest cross-section passing from a much larger one).

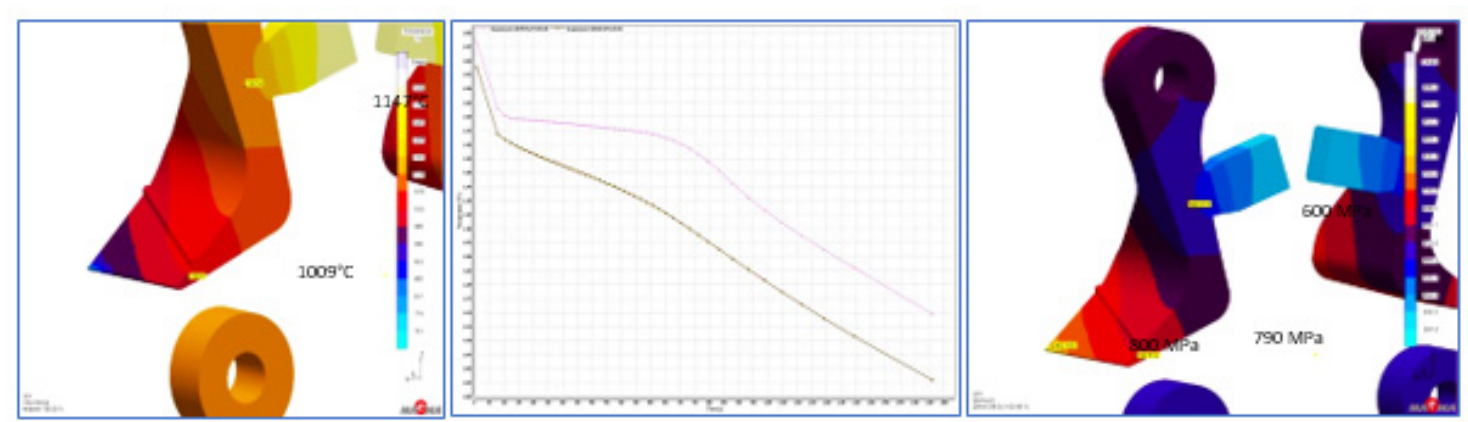

Figure 6: Measurement points(left), kinetics of temperature changes during solidification (centre) and strength values at various points of the casting (right).

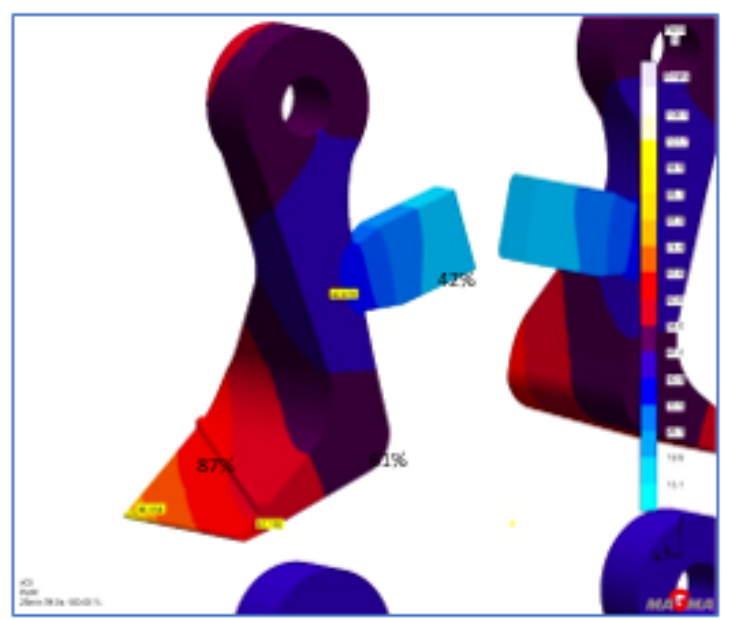

Figure 7: Virtual evaluation of the amount of perlite in the cross-section of the casting 


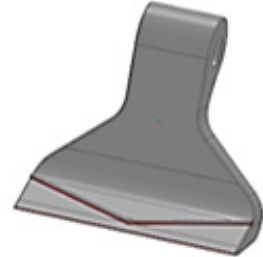

CAD model

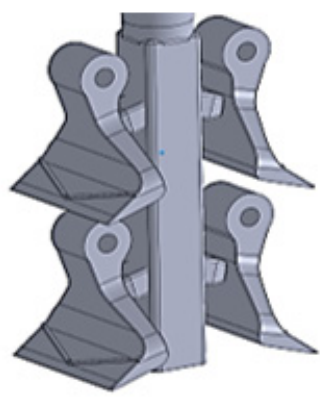

technological variant

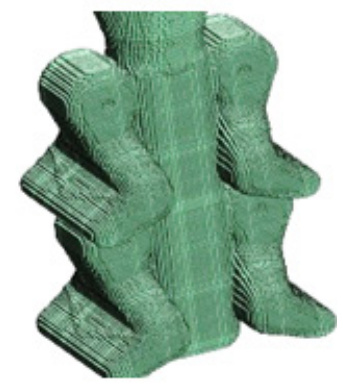

virtual mould

Figure 8: The RM4 type mulcher selected for the numerical analysis of the casting residual stress.

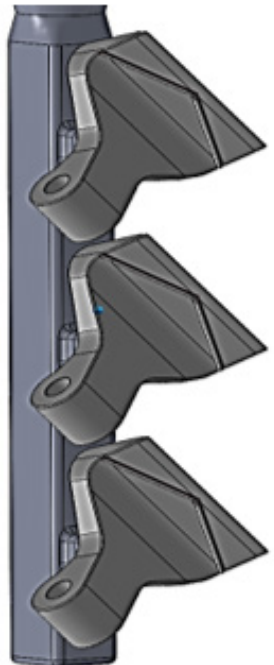

A

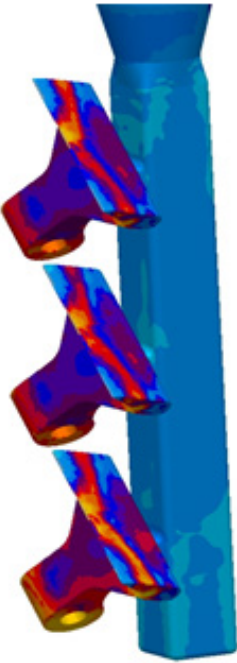

A1

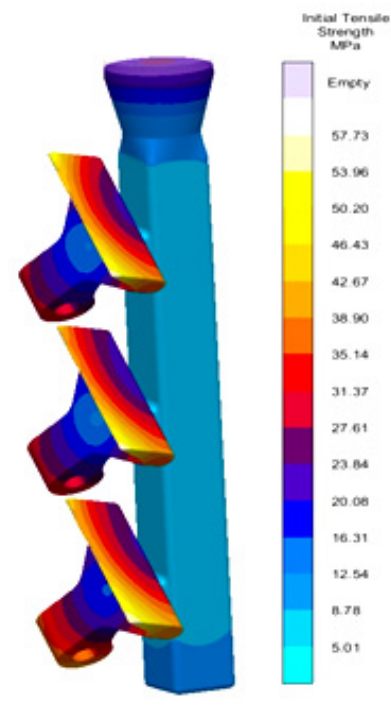

A2

Figure 9: Variant A. Set with three models of the RM4 mulcher and visualization of the stress simulation results: A1 - on the Von Mises scale - the reduced stresses value.

A2 - on the Initial Tensile Strength scale - tensile stresses during solidification of liquid metal.

Perform the operation of removing the gating system will reduce the value of residual stress-es, i.e. those arising in the technological process. The application of heat treatment will cause relaxation and elimination of stresses arising after the solidification casting process (stresses resulting from the essence of the solidification process and the resistance of the ceramic mould).

Control castings made according to the developed technology Figure 11 were evaluated using a 3D scanner to determine the dimension accuracy with the design CAD drawings, as shown in Figure 12.

The observed slight dimensional deviations in places important from the operational point of view, which were shown by the performed measurements, do not have a significant effect on the functional features of the tool.

\section{Conclusions}

a. Realizing the project work described in the article, the main goals were achieved, namely:

1. An analysis of the design and operational requirements for foundry materials for the production of new tools for the forestry sector,

2. Properties necessary for the development of virtual and real casting technology have been determined for the selected casting alloys,

3. Temperature and time parameters of thermal treatments were determined in order to optimize the mechanical and functional properties of alloys recommended for new, cast working parts of machines and devices used in forestry. 
b. Comparing the obtained results of laboratory material tests, it was found that the 30MCDB64-MI cast steel, after a properly selected heat treatment process, does not differ in its properties from the forged steel of reference tools. Technological process of its production is less expensive than the other selected for the tests of cast steel grades (30NSCDV86-M). This alloy, apart from good tribological resistance and high strength parameters, does not meet other design requirements (high brittleness) and operational requirements (poor corrosion resistance). Therefore, cast steel 30MCDB64-M-I was selected for further work. In order to obtain the appropriate balance of strength and plasticity, its chemical composition and technological parameters of the necessary thermal treatments were slightly modified. These parameters slightly different from those specified in the relevant standards, which, apart from the construction of the hammerhead, was included in the submitted patent application [11]. c. Measurements of the geometry of selected hammer heads showed that the stresses that arise during the solidification and cooling process for the analyzed manufacturing concepts of the implemented tools are below the yield point of the material used and do not cause its de-formation.

d. Quality assessment, including the lack of significant dimensional deviations in the areas of construction ally significant for mulchers castings, confirmed of the numerical analysis results carried out in the field of virtual technology development, both in terms of shrinkage porosity and not exceeding the admissible casting stresses causing excessive deformation of the casting.

e. The manufactured test series of mulchers (6 types, over 250 examples), after laser surfacing by the Project Consortium (SBL-PIMR) of the working layers with the special mixtures of metallicceramic powders, were sent for operational tests as spare parts for the of forestry machinery.

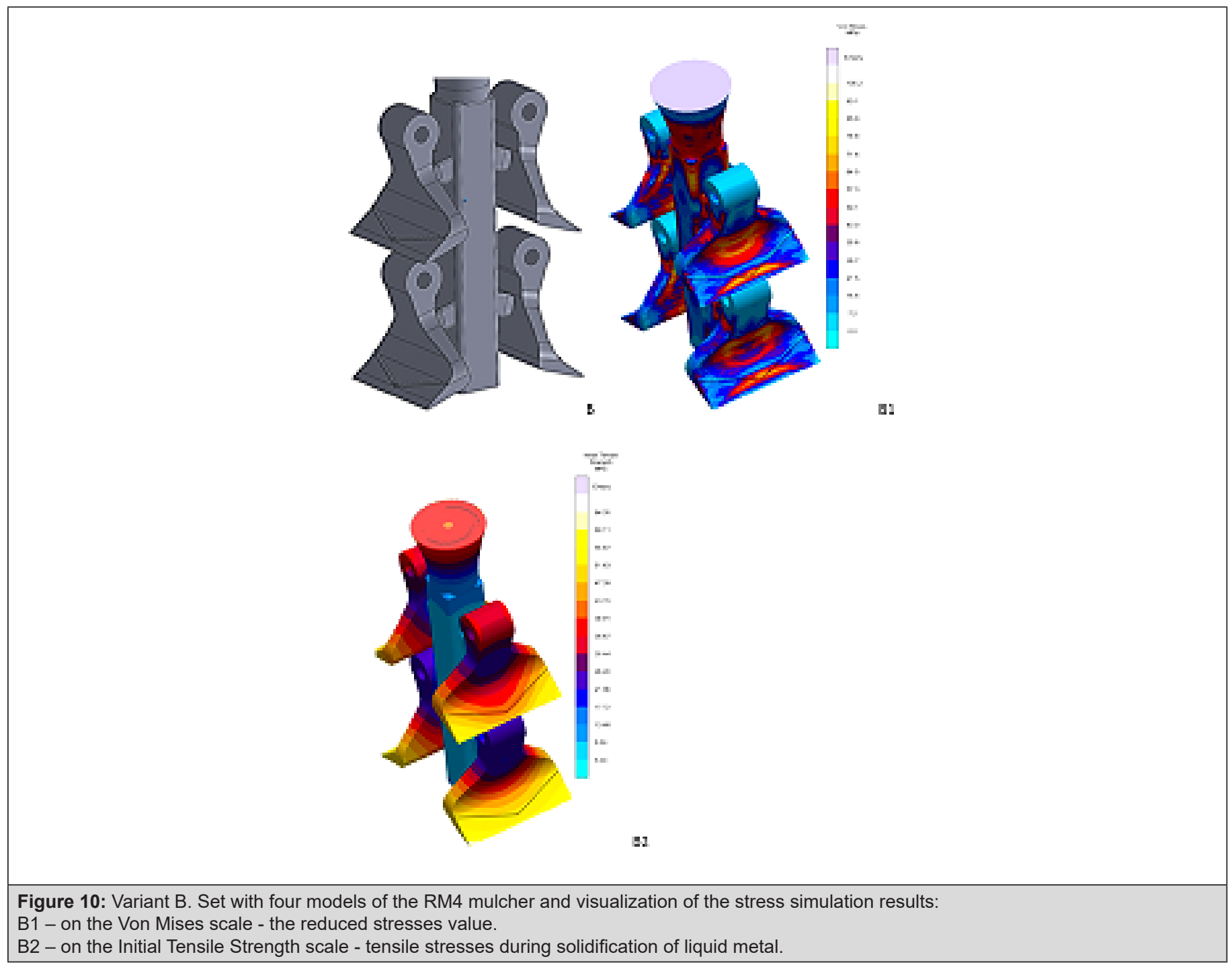




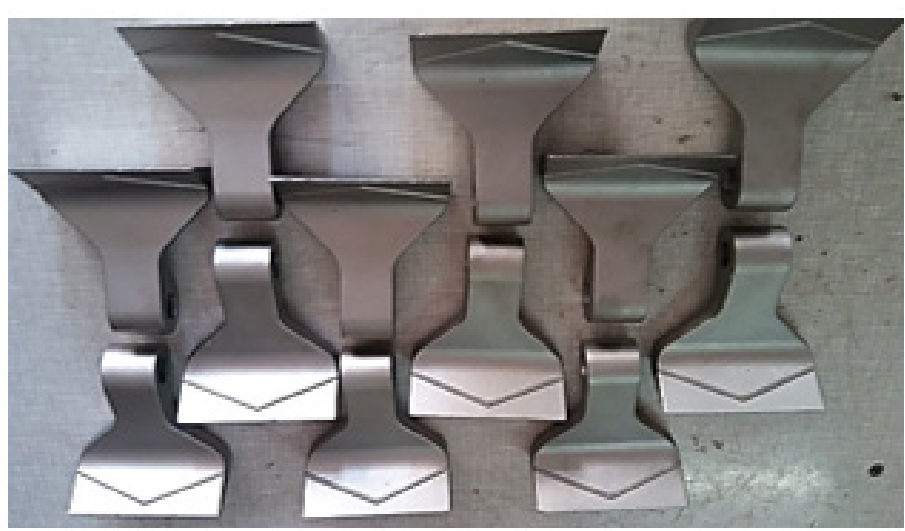

Figure 11: Manufactured casts of RM4 mulchers.
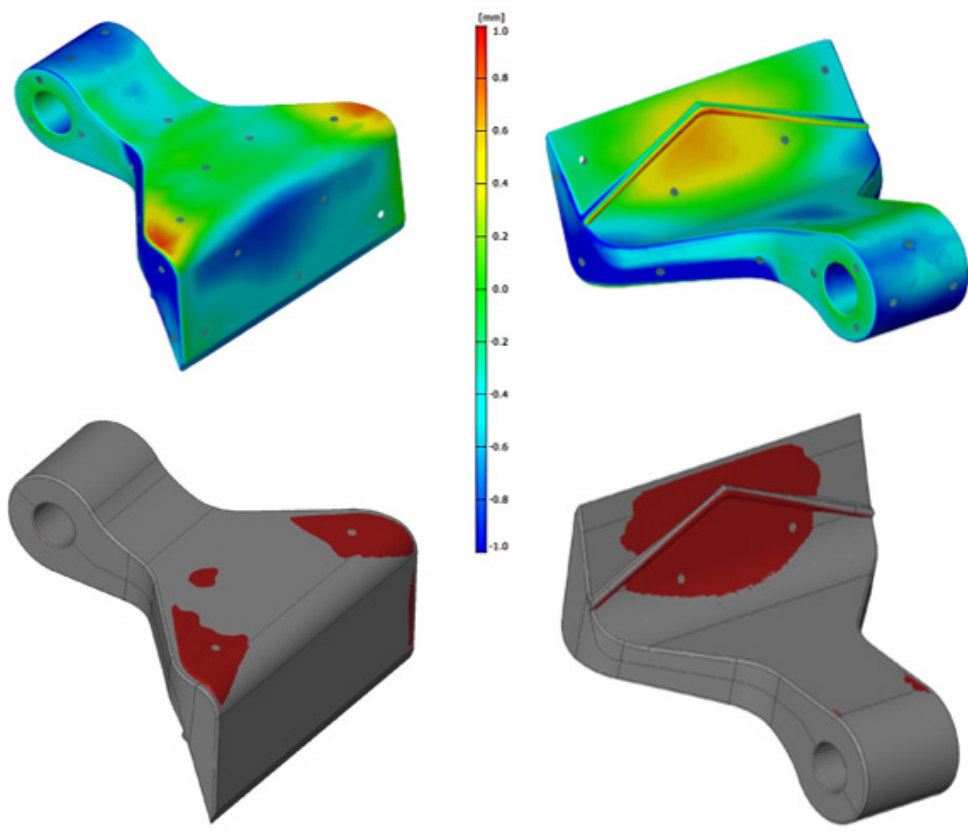

Figure 12: Measurements of dimensional deviations of the RM4 mulcher castings and matching the casting scan to the CAD model with the best fit method.

\section{Acknowledge}

The article was created as a result of the work carried out under the "Modern Material Technologies " TECHMATSTRATEG 1 program as part of the project with the acronym INNOBIOLAS entitled " Development of innovative working elements of machines in the forestry sector and biomass processing based on high-energy technologies of surface modification of the surface layer of cast elements"; agreement no. TECHMATSTRATEG1 / 348072/2 / NCBR / 2017.

The authors of the article would like to thank the coimplementers of the project from SBL-PIMR, especially $M$. Goscianski, D. Kapcinska-Popowska and colleagues from SBL-KIT for their help in realization of project, in particular M. Warmuzek, $P$. Turalska, I. Krzak, L. Boron and M. Wojcicki.

\section{References}

1. December M (2018) Selection of multi-phase casting materials enabling the transfer of high loads in conditions of tribological wear of the forestry sector tools; Conference. Construction materials and protective coatings for agricultural, forestry and food machines Poznan.

2. Kęsik T, Konopinski M, Blazewicz Wozniak M (2006) Effect of prewinter cultivation and mulch from covering plants on water retention, compaction and differential porosity of soil after overwintering. Acta Agrophys 7(4): 915-926.

3. Pirowski Z, Goscianski M (2013) Casting Alloys for Agricultural Tools Operating under the Harsh Conditions of Abrasive Wear, TEKA. COMMISSION OF MOTORIZATION AND ENERGETICS IN AGRICUL-TURE 13(1): 119-126. 
4. Pirowski Z, Gwizdz A, Kranc M (2012) Cast Agricultural Tools Operating in Soil, Naukovij Visnik Nacion-al'nogo Universitetu Bioresursiv i Prirodokoristuvannia Ukraini, Serija: Tekhnika ta energetika APK 170(1): 378-385

5. Goscianski M, Pirowski Z (2009) Construction and Technology of Production of Casted Shares for Rotating and Field Plows, Teka Commission of Motoryzacji i Energetyki Rolnictwa O L PAN 9(9): 231239.

6. Pirowski Z, Olszynski J, Turzynski J, Goscianski M (2006) Elements of agricultural machinery working in soil made of modern casting materials; Motrol. Automotive and Energy of Agriculture 8: 169-180.

7. Malysza M, Wieliczko P, Dziedzic S (2019) Technological aspects of producing castings of selected tools for the forestry sector; Conference Construction materials and protective coatings for agricultural, forestry and food machines; Poznan, 24.10

8. NF A 32-058 / 1984: PRODUITS DE FOUNDERIE ACIERS ET FONTES BLANCHES MOULES RESISTANT A L'USURE PAR ABRASION.

9. Homa M, Pirowski Z, Turalska P, Bitka A, Jaskowiec K (2019) Thermophysical properties of 30MCDB64-M and 30NSCDV86-M cast steel in the cast condition. Journal of Applied Materials Engineering $59(2)$.

10. Kapcinska Popowska D, Goscianski M, Drozd M (2019) Study of selected performance properties of composite welds based on Ni-WC alloy powders; Conference "Construction materials and protective coatings for agricultural, forestry and food machines"; Poznan, 24.10.

11. Patent application: Hammer hammer of a mulcher and the method of its production; Report number: P.431587; Date of notification: October $25,2019$.
12. Pirowski Z (2015) Thermal analysis in the technological "Step" Test of H282 nickel alloy; Archives of Foundry Engineering. Open Access 15(1): 87-92.

13. Pirowski Z, Warmuzek M, Radzikowska J Test casting Inconel 740 alloy; 70th World Foundry Congress 2012, WFC 20122012, Pages 56056570th World Foundry Congress 2012, WFC 2012; Monterrey; Mexico; 25 April 2012 through 27 April 2012 (Conference Paper).

14. Sobczak JJ, Purgert RM, Pysz S, Malysza M, Sobczak N, et al. (2014) Numerical analysis of the casting process of H282 alloy; 71st World Foundry Congress: Advanced Sustainable Foundry, WFC 2014201471st World Foundry Congress: Advanced Sustainable Foundry, WFC 2014; Palacio Euskalduna Bilbao; Spain; 19 May 2014 through 21 May 2014 (Conference Paper).

15. Pirowski Z, Jaskowiec K, Tchorz A, Krzak I, Sobczak J J, et al. (2016) Technological conversion applicable for manufacturing elements from Nickel superalloy H282; 72nd World Foundry Congress, WFC 20162016 , Pages 223-22472nd World Foundry Congress, Japan.

16. Grudzien Rakoczy M, Rakoczy L, Cygan R, Pirowski Z, et al. (2020) Fabrication and Characterization of the Newly Developed Superalloys Based on Inconel 740. MATERIALS 21,13(10):2362.

17. Pirowski Z, Bitka A, Grudzien Rakoczy M, Uhl W, Wilk Kolodziejczyk D, et al. (2020) Low-alloy, abrasion-resistant cast steel to replace traditional plastically processed steel grades; Crystals, (w druku). 